\title{
Restricting Dopaminergic Signaling to Either Dorsolateral or Medial Striatum Facilitates Cognition
}

\author{
Martin Darvas and Richard D. Palmiter \\ Howard Hughes Medical Institute and Department of Biochemistry, University of Washington, Seattle, Washington 98195
}

Dopaminergic projections to the ventral and dorsomedial striatum are important for reward, motivation, and goal-directed learning, whereas projections to the dorsolateral striatum are implicated in motor control, habitual enactment of motor skills, visuospatial learning, and memory. These conclusions are derived from studies of rodents with lesions or pharmacological blockade of dopamine signaling to specific brain regions. In contrast, we investigated the behavioral abilities of dopamine-deficient mice in which dopamine signaling was restored to only the medial striatum by viral rescue. These mice displayed intact spatial memory, visuospatial and discriminatory learning. However, acquisition of operant behavior was delayed, and their motivation to obtain food rewards was blunted. We compare these behavioral results with our published results obtained from mice with dopamine signaling restored only to the dorsolateral striatum. We observe that most behaviors are restored with dopamine signaling restored to either brain region and conclude that the action of dopamine in either one of these nonoverlapping striatal areas can support cognitive processes independently of dopamine signaling in the other area.

\section{Introduction}

Midbrain dopamine (DA) neurons of the ventral tegmental area (VTA) and substantia nigra pars compacta $(\mathrm{SNc})$ play a crucial role in motor control and in emotional and cognitive processes (Wise, 2004). Dopaminergic neurons from the VTA send projections to the prefrontal cortex, hippocampus, amygdala, and the ventral striatum, whereas DA neurons from the SNc project primarily to the dorsal striatum (Björklund and Dunnett, 2007). Dopaminergic projections that originate in the VTA and project to the prefrontal cortex (PFC) are thought to regulate attentional processes and working memory (Dalley et al., 2004), whereas VTA projections to the ventral striatum are assumed to play a key role in reward, motivation, and goal-directed learning (Wolterink et al., 1993; McFarland and Ettenberg, 1995; Smith-Roe and Kelley, 2000; Ikemoto, 2003). Dopaminergic projections that originate in the SNc are traditionally considered to control motor output and stimulus-response learning (Featherstone and McDonald, 2004; O’Doherty et al., 2004; Nakamura and Hikosaka, 2006). However, recent evidence indicates that goal-directed behaviors depend on signaling in the dorsomedial striatum and prefrontal cortex (Graybiel, 2008; Yin et al., 2008). In addition, data from rodents with neurotoxic lesions of nigrostriatal DA neurons indicate that the dorsal striatum also strongly contributes to visuospatial function and memory (Baunez and Robbins, 1999; Da

Received Sept. 15, 2009; revised Nov. 12, 2009; accepted Nov. 30, 2009.

We thank Valerie Wall for maintaining the DD mouse colony, Glenda Froelick for preparing histological sections, and Dr. Miguel Chillon (Vector Production Unit, Centre de Biotecnologia Animal i Teràpia Gènica, Universitat Autonoma Barcelona, Barcelona, Spain) for preparing the CAV2-Cre virus. We also thank Dr. Satoshi Ikemoto and Dr. Peter Dayan for helpful discussions during the preparation of this manuscript.

Correspondence should be addressed to Richard D. Palmiter at the above address. E-mail: palmiter@ u.washington.edu.

D01:10.1523/JNEUROSCI.4576-09.2010

Copyright $\odot 2010$ the authors $\quad 0270-6474 / 10 / 301158-08 \$ 15.00 / 0$
Cunha et al., 2002; Mura and Feldon, 2003; Chudasama and Robbins, 2006; De Leonibus et al., 2007).

Most previous studies that examined the function of specific striatal regions use techniques that reversibly block striatal output neurons, ablate DA projections to the striatum, or lesion striatal subregions. Our laboratory has generated a genetic model, the DA-deficient (DD) mouse that permits one to assess the behavioral effects of region-specific restoration of DA signaling to mice that lack DA signaling in all other brain regions. DD mice have inactive $T h$ alleles that can be reactivated in a regionspecific manner through retrograde transport from the site of injection of a Cre recombinase-expressing virus (Hnasko et al., 2006). Untreated DD mice have severe deficits in motivation and locomotion and will not perform tasks that require intentional movement (Palmiter, 2008). Because anatomical studies suggest that a dorsolateral to ventromedial distinction may be more appropriate than a simple dorsal to ventral distinction (Voorn et al., 2004), we opted for injecting the Cre recombinase-expressing virus into the ventromedial (VM) striatum and examine the role of DA signaling to this area in learning, memory, and motivation. Then we compare the results with those obtained in mice in which the virus was injected into the dorsolateral (DL) striatum (Darvas and Palmiter, 2009).

\section{Materials and Methods \\ Drugs \\ L-3,4-Dihydroxyphenylalanine (L-Dopa) (Sigma-Aldrich) was dissolved in saline solution containing $0.25 \%$ ascorbic acid and then filtered. Caf- feine (Sigma-Aldrich) was dissolved in saline solution. All drugs were administered intraperitoneally.}

\section{Animals}

All experiments were approved by the Institutional Animal Care and Use Committee at the University of Washington. The DD mice were generated as described previously (Hnasko et al., 2006). Mice were maintained 
on a mixed C57BL/ $6 \times 129 / \mathrm{SvEv}$ genetic background and were housed under a $12 \mathrm{~h}$ light/dark cycle in a temperature-controlled environment with food and water available ad libitum unless noted otherwise. Canine adenovirus 2 expressing Cre recombinase (CAV2-Cre) virus was generated and titered as described previously (Kremer et al., 2000). The virus preparation had a titer of $6 \times 10^{12}$ particles per milliliter. Bilateral injections of $0.5 \mu \mathrm{l}$ of CAV2-Cre into the VM region of the striatum $(0.9 \mathrm{~mm}$ anterior to bregma, $\pm 1.0 \mathrm{~mm}$ lateral to midline, $4.8 \mathrm{~mm}$ ventral from the skull surface) were performed on anesthetized (isoflurane) 2- to 3-month-old male and female DD or control mice (referred to as sham controls). Virally injected DD mice were removed from L-Dopa treatment 2 weeks after viral injection, and those mice that maintained body weight after 1 week without L-Dopa treatment were designated as vrDD-VM mice and allowed 1 more week of recovery before behavioral testing began. DD mice (whether treated with caffeine or L-Dopa) received daily L-Dopa injections at least $6 \mathrm{~h}$ after completion of the experimental sessions.

\section{Behavioral studies}

DD mice do not perform behavioral tasks that require voluntary movements. Therefore, we used pharmacological procedures that allow them to execute the explorative aspects of the tasks either in a DA-depleted or DA-replete state. One group of DD mice performed the explorative aspects of the tests in a DA-depleted state and therefore received $15 \mathrm{mg} / \mathrm{kg}$ caffeine $10 \mathrm{~min}$ before habituation or training sessions in all tests. These DD mice were then tested $15 \mathrm{~min}$ after injection with L-Dopa $(30 \mathrm{mg} / \mathrm{kg})$. A different group of DD mice was habituated, trained, and tested $15 \mathrm{~min}$ after injection with L-Dopa (30 $\mathrm{mg} / \mathrm{kg}$ ). The same groups of vrDD-VM and sham mice were used for all experiments. Behavioral experiments with DD mice and vrDD-VM mice were performed in the order listed below with at least $14 \mathrm{~d}$ between experiments.

Locomotor activity. Locomotor activity was assessed in locomotor chambers equipped with photobeams (Columbus Instruments) and monitored for $4 \mathrm{~d}$ after an initial acclimatization phase of $12 \mathrm{~h}$.

Object recognition test. For the object recognition test, object exploration was measured during a 6 min test in a circular open-field arena (45 $\mathrm{cm}$ diameter) as time spent exploring a concomitantly presented novel and sample object. Exploration was scored by measuring the time when mice made direct contact (mouth, nose, or paw) with an object that was not accidental or incidental. The scoring was done in a blinded manner. Object recognition was calculated as percentage of total time spent exploring the novel object. One day before the testing, mice were habituated to a pair of identical sample objects during three consecutive 6 min trials. A hemispherical and an oblong plastic object, each $\sim 7 \mathrm{~cm}$ high, were used as sample and novel object.

Morris water maze. The Morris water maze was used to assess visuospatial learning and spatial reference memory. Mice were trained to locate a hidden platform over a period of $8 \mathrm{~d}$ with four $90 \mathrm{~s}$ trials per day. On each trial, mice were released into the pool from a different location. All sessions were recorded with a camera and analyzed with EthoVision software (Noldus). The circular pool was $84 \mathrm{~cm}$ in diameter and filled with opaque water at $22^{\circ} \mathrm{C}$. No visual cues were present within the pool. External cues were provided through the wall decoration of the room. Visuospatial learning was measured as latency to reach the hidden platform. Swim speed was also recorded. One day after the fourth and eighth training sessions, mice performed a $90 \mathrm{~s}$ spatial memory trial in which no platform was present in the maze, which was scored as the percentage of time spent in the quadrant of the pool where the platform was positioned during training.

Discrimination learning. Discrimination learning was measured as percentage of correct trials per day in a water-based, U-shaped maze. Mice were released into a gray stem $(45 \mathrm{~cm})$ that ended in one black and one white choice arm $(50 \mathrm{~cm})$, which bent back toward the stem so that the mouse could not see the escape platform at the end of the positive arm (Gorski et al., 2003). For one-half of the mice, the escape arm was white, and for the other half it was black. Mice were trained for $5 \mathrm{~d}$ with 10 trials per day. The right-left orientation of the correct arm of the maze was alternated in pseudorandom sequence each day.
Instrumental learning. For instrumental learning, mouse operant chambers (MED Associates) were used. Mice were maintained at 85\% of ad libitum body weight for the duration of this experiment. Training consisted of 18 daily sessions with each session lasting until 50 rewards were earned or $2 \mathrm{~h}$ passed. Two levers were available during each session, with the depression of either one resulting in the delivery of one $20 \mathrm{mg}$ food pellet (BioServe). For the break point analysis, the number of lever presses required for food delivery increased according to a nonarithmetic schedule that increased response requirements as described by Robinson et al. (2007). Briefly, the number of lever presses to earn a reinforcer increased in the following manner: $01,02,04,06,09,12,15,19,22,26,30,35,40,45,50,55$, etc. The break point session lasted $3 \mathrm{~h}$ with no limit to the number of rewards that could be earned.

\section{Immunohistochemistry and DA measurement}

Proteins were detected on $30 \mu \mathrm{m}$ brain sections by using the following primary antibodies: rabbit anti-tyrosine hydroxylase (TH) (1:2000; Millipore Bioscience Research Reagents) and rat anti-DA transporter (1:1000; Millipore Bioscience Research Reagents). Immunofluorescence was revealed by using CY2 (TH)- and/or CY3 (DA transporter)-labeled IgG secondary antibodies (1:200; Jackson ImmunoResearch). For determination of striatal DA content, punches ( $0.5 \mathrm{~mm}$ diameter; $2 \mathrm{~mm}$ thick) from brain regions of interest were collected, immediately frozen in liquid nitrogen, and stored at $-80^{\circ} \mathrm{C}$ until analysis. HPLC coupled with electrochemical detection was used to measure DA content by the Neurochemistry Core Laboratory at the Center for Molecular Neuroscience Research of Vanderbilt University (Nashville, TN).

\section{Results}

\section{Restoration of dopaminergic signaling to the VM striatum}

To assess the function of the VM striatum in learning, memory, and motivation, we selectively restored dopaminergic signaling in DD mice by bilaterally injecting CAV2-Cre into the VM striatum. The virus was retrogradely transported and activated Th gene expression in dopaminergic neurons within the VTA. Based on our previous work showing that feeding can be restored to DD mice with viral injections into the striatum (Szczypka et al., 2001; Hnasko et al., 2006), only those mice in which feeding was restored were used for the following experiments; they are referred to as virally rescued or vrDD-VM mice. The control mice for these experiments (sham controls) were also injected with CAV2Cre at the same coordinates, but they already have an intact $T h$ allele.

$\mathrm{TH}$ expression was restored to dopaminergic neurons in the VTA of vrDD-VM mice (Fig. $1 A-D$ ), whereas only a few THexpressing cells could be observed in the SNc of $\mathrm{VrDD}-\mathrm{VM}$ mice (Fig. 1 $A-D$ ). In the striatum, TH immunostaining was restored mainly to the core of the nucleus accumbens (Acb) and to the dorsomedial (DM) striatum, with some staining in the shell of the Acb and the olfactory tubercle (Fig. $1 E-H$ ). The DL striatum of vrDD-VM mice was completely devoid of TH staining (Fig. $1 \mathrm{E}-$ $H)$. Higher resolution images of $\mathrm{TH}$-stained sections from vrDD-VM mice show only a minimum amount of TH-positive immunostaining in the dorsolateral and ventrolateral striatum (supplemental Fig. 1, available at www.jneurosci.org as supplemental material). To estimate the anterior-posterior extension of $\mathrm{TH}$ immunostaining in the medial striatum of vrDD-VM mice, we also analyzed saggital sections. TH immunostaining was abundantly restored in the ventromedial striatum along the full anterior-posterior axis; TH expression in the dorsomedial striatum also extended along the anterior-posterior axis in a uniform manner, but the intensity of TH immunostaining was less intense than in the ventromedial striatum (supplemental Fig. 2, available at www.jneurosci.org as supplemental material). Quantitative analysis of DA and its metabolites by HPLC-electrochemical de- 
tection revealed that DA in the VM striatum was restored to $\sim 26 \%$ and in the DM striatum to $\sim 18 \%$ of control levels (Table 1). DA content in the DL striatum was $\sim 2 \%$ and in the VL (ventrolateral) striatum $\sim 4 \%$ of control levels, similar to levels found in DD mice (Szczypka et al., 2001). Striatal subregions and a more detailed representation of the minimal and maximum amounts of DA restoration in the striatum of vrDD-VM mice are depicted in supplemental Figures 3 and 4 (available at www.jneurosci.org as supplemental material).

\section{Feeding and locomotion are restored in vrDD-VM mice}

After surgery, the DD mice were maintained on L-Dopa for $14 \mathrm{~d}$ to allow viral reactivation of the conditionally inactive Th genes. The vrDD-VM mice were no longer dependent on L-Dopa for survival and were able to maintain their body weight (Fig. 2A). Locomotor activity by the vrDD-VM mice over a $24 \mathrm{~h}$ period was the same as sham controls mice that were injected with CAV2-Cre (Fig. 2B).

\section{Memory and visuospatial learning are restored in vrDD-VM mice}

Because DD mice do not perform any of the following tests (Darvas and Palmiter, 2009), we used caffeine in one group of DD mice to restore activity independently of DA signaling and L-Dopa in another group to test the abilities of DD mice with DA signaling restored to all brain regions. To assess the function of dopaminergic signaling in the VM striatum for memory, we first examined sham control, vrDD-VM, and caffeine- or L-Dopa-stimulated DD mice with an object recognition test. Only sham control animals $(p<0.01)$ and DD mice that were stimulated during all trials with L-Dopa $(p<0.05)$ spent significantly more time exploring the novel object during the preference choice test, as confirmed with a $t$ test for differences of mean preferences from 50\% (Fig. 3A). However, analysis of the total time spent exploring the sample objects during the first habituation trial showed that sham control, caffeine- and L-Dopa-treated DD mice had similar object exploration, whereas vrDD-VM mice displayed a strong reduction in object exploration (ANOVA, $F_{(3,31)}=9.74, p<0.01$; Bonferroni's post hoc comparison, $p<0.01$ for vrDD-VM against any other group) (Fig. $3 B$ ). Because the vrDD-VM mice did not explore the objects, it was not possible to draw a conclusion about their object memory.

In the Morris water maze, vrDD-VM mice were able to swim and to locate the hidden platform over the course of training (Fig. $3 C)$. Two-way ANOVA of the escape latencies revealed significant effects for both training day $\left(F_{(7,244)}=9.12 ; p<0.01\right)$, group factors $\left(F_{(3,244)}=67.01 ; p<0.05\right)$, and interaction between day and group factors $\left(F_{(21,244)}=3.01 ; p<0.01\right)$. Sham control, L-Dopa-treated DD and vrDD-VM mice had no differences in escape latencies, as shown by Bonferroni's post hoc comparison $(p>0.05)$. Caffeine-treated DD mice did not decrease their escape latencies over the course of training and retained significantly higher escape latencies (each $p<0.01$ ) when compared
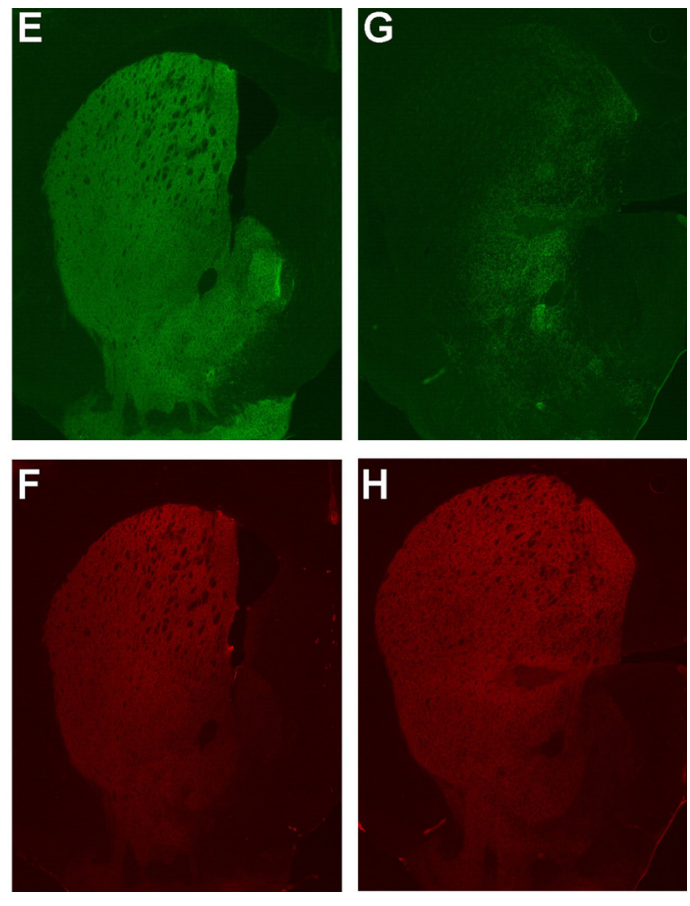

Restoration of dopaminergic signaling in midbrain and striatum of vrDD-VM mice. TH (green) and dopamine transreveal projections of midbrain DA neurons in control $(\boldsymbol{E}, \boldsymbol{F})$ and $\operatorname{vrDD}$-VM mice $(\boldsymbol{G}, \boldsymbol{H})$. TH staining was primarily present in the medial striatum of vrDD-VM mice. The lateral parts of the striatum were devoid of TH signal in vrDD-VM mice.

Table 1. Tissue content of dopamine and its metabolites in the striatum

\begin{tabular}{lcccc}
\hline Region & $\mathrm{n}$ & DA (\% control) & HVA (\% control) & DOPAC (\% control) \\
\hline Dorsolateral & 5 & $2.14 \pm 1.16$ & $8.66 \pm 3.75$ & $5.86 \pm 1.28$ \\
Dorsomedial & 5 & $18.37 \pm 5.23$ & $21.94 \pm 4.40$ & $41.37 \pm 11.00$ \\
Ventromedial & 5 & $26.86 \pm 5.81$ & $20.45 \pm 3.68$ & $20.27 \pm 4.57$ \\
Ventrolateral & 5 & $3.95 \pm 1.05$ & $6.29 \pm 1.74$ & $6.96 \pm 1.16$ \\
\hline
\end{tabular}

Data are presented as means \pm SEM. DA, dopamine; HVA, homovanillic acid; DOPAC, 3,4-dihydroxyphenylacetic acid.

with other groups. Two-way ANOVA of swim speed showed a significant effect for the group factor only $\left(F_{(3,244)}=38.81 ; p<\right.$ $0.01)$, with similar swim speeds for L-Dopa- or caffeine-treated DD mice and vrDD-VM mice that were slightly lower than that of control mice (Fig. 3D). Analysis of the probe trials after $4 \mathrm{~d}$ of training (ANOVA with Bonferroni's post hoc test) confirmed significant preferences for the quadrant where the platform was hidden during training for sham control $\left(F_{(3,39)}=16.94 ; p<\right.$ $0.01)$, L-Dopa-treated DD $\left(F_{(3,23)}=10.12 ; p<0.01\right)$, and $\operatorname{vrDD}-\mathrm{VM}$ mice $\left(F_{(3,39)}=11.63 ; p<0.01\right)$ (Fig. $\left.3 E\right)$. Whereas sham control and L-Dopa-treated DD mice preferred the target quadrants significantly over all other quadrants, vrDD-VM mice preferred the target quadrant only over quadrants 1 and 3 . Analysis of the probe trials (ANOVA with Bonferroni's post hoc test) after $8 \mathrm{~d}$ of training confirmed significant preferences for the quadrant where the platform was hidden during training for sham control $\left(F_{(3,39)}=24.22 ; p<0.01\right)$, L-Dopatreated $\mathrm{DD}\left(F_{(3,23)}=4.88 ; p<0.05\right)$, and vrDD-VM mice $\left(F_{(3,39)}=19.89 ; p<0.01\right)($ Fig. $3 F)$. DD mice that were trained with caffeine and then tested after injection of L-Dopa (30 $\mathrm{mg} / \mathrm{kg}$ ) had no preference for the target quadrant. We con- 


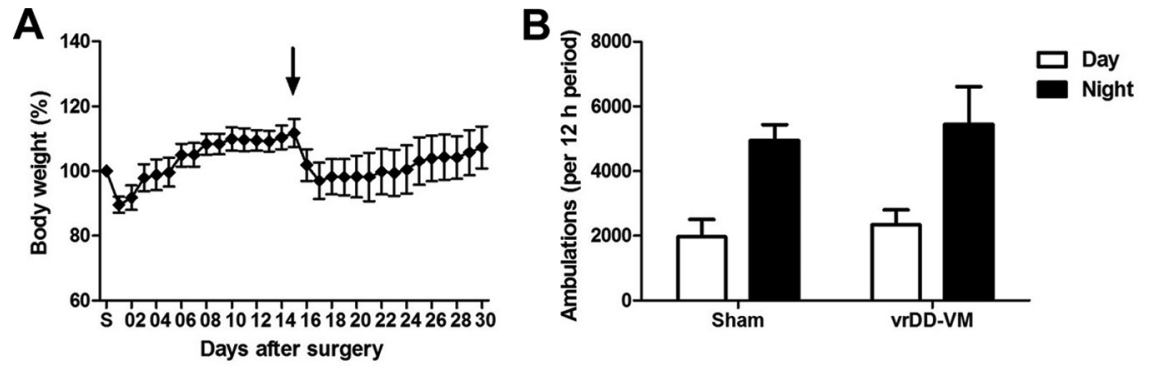

Figure 2. $\quad A$, Body weight (BW) of vrDD-VM mice $(n=10)$ after bilateral injection of CAV2-Cre into the VM striatum. Weight is shown as percentage of BW on the day of surgery. The black arrow denotes when daily L-Dopa treatment was stopped ( 2 weeks after surgery). Those mice that continued to gain weight are designated vrDD-VM. Untreated DD mice stop eating, lose body weight, and die within $\approx 3 \mathrm{~d}$ without L-Dopa (data not shown). BW of vrDD-VM mice typically stabilized at $\sim 80 \%$ that of control littermates $1-3$ months after surgery. $\boldsymbol{B}$, Locomotor activity (measured by ambulations) by sham control $(n=8)$ and vrDD-VM mice $(n=10)$ during day (white bars) and night (black bars). Locomotor activity was restored to control level in vrDD-VM mice. Data are expressed as mean \pm SEM.

clude that visuospatial learning and memory in this task were restored in vrDD-VM mice.

\section{Cue-dependent learning is restored in vrDD-VM mice}

We also tested DD and vrDD-VM mice in a cue-dependent, discriminatory water-based U-maze. In this maze, mice swim to a choice point where they can see a cue indicating which of the two bent arms contains an escape platform. The location of the correct arm (left vs right) was varied randomly and mice were given 10 trials per day for $5 \mathrm{~d}$. Two-way ANOVA of the percentage of correct trials per day revealed significant effects of group $\left(F_{(3,140)}=24.18 ; p<0.01\right)$, number of training days $\left(F_{(4,140)}=20.40 ; p<0.01\right)$ (Fig. $\left.3 G\right)$, and interaction between day and group factors $\left(F_{(4,140)}=2.33 ; p<0.05\right)$. As confirmed by Bonferroni's post hoc comparisons, there were no significant differences in learning between sham control, L-Dopatreated DD and vrDD-VM mice $(p>0.05)$. Caffeine-treated DD mice did not improve their performance and differed significantly after the second training day from all other groups $(p<0.05)$, which all showed increased performance over the course of training. We conclude that restitution of DA signaling in $\mathrm{vrDD}-\mathrm{VM}$ mice restored discriminatory learning.

\section{Acquisition of instrumental reward learning is impaired in vrDD-VM mice}

Previous experiments have shown that DA is necessary for operant conditioning in a simple lever-pressing paradigm for food rewards (Robinson et al., 2007). We used the same operantconditioning paradigm to examine learning and motivation by vrDD-VM mice. The overall pattern of results showed that vrDD-VM mice learned the instrumental lever-pressing response (Fig. 4A). They improved the number of lever presses per session significantly over the course of training (ANOVA, $F_{(17,161)}=$ 5.04, $p<0.01$ ), but still retained an acquisition deficit when compared with sham control mice (two-way ANOVA, $F_{(1,306)}=$ $126.09, p<0.01$; Bonferroni's post test, $p<0.01$ for days $01-05$ and $p<0.05$ for days $06-08$ ) (Fig. $4 A$ ). To test the possibility that lever press responses by vrDD-VM mice resulted from reduced activity in the operant chambers, we also measured the number of food receptacle entries during all training sessions; vrDD-VM had significantly $(p<0.01)$ reduced magazine entries on the first day of training but had similar number of entries as sham control mice during the remaining training days (Fig. $4 B$ ). To assess their motivation to work for rewards, we tested vrDD-VM mice under a $3 \mathrm{~h}$, progressive-ratio training schedule. Two-way ANOVA of

\section{Discussion}

the cumulative number of rewards earned per 5 min bin revealed significant effects of group $\left(F_{(1,595)}=20.03 ; p<0.01\right)$, time point $\left(F_{(35,595)}=58.39 ; p<0.01\right)$ (Fig. $4 C)$, and interaction between day and group factors $\left(F_{(35,595)}=7.412 ; p<0.01\right)$. As confirmed by Bonferroni's post hoc comparisons, after $40 \mathrm{~min}$ all differences between sham and vrDD-VM mice were significant, suggesting that motivation to work for food rewards is strongly impaired in vrDD-VM mice. We assessed the break point as the time point at which the mice stop lever pressing for $>15 \mathrm{~min}$. Sham mice stopped responding after $\sim 86 \mathrm{~min}$ and vrDD-VM mice stopped after $\sim 38 \mathrm{~min}$, significantly earlier than sham mice ( $t$ test, $p<0.05)$.

\section{Comparison of the abilities of naive DD, vrDD-VM, and vrDD-DL mice}

A direct comparison of the abilities that are restored in vrDD-VM mice with results from our previous study with DD mice that have DA signaling restored to the dorsolateral striatum, vrDD-DL (Darvas and Palmiter, 2009), shows that DD mice could not perform any of the tasks, whereas the performance of most tasks by both groups of virally rescued mice was essentially the same as sham controls (Table 2). Among these tasks, the only difference between the virally rescued mice is that object exploration that was restored in vrDD-DL mice was not restored in vrDD-VM mice, and vrDD-VM mice had a larger motivational deficit. The vrDD-DL mice were reanalyzed using the same procedure as with the vrDD-VM mice (supplemental Fig. 5, available at www.jneurosci.org as supplemental material). Motivation was estimated as the time point during the progressive-ratio schedule at which animals stopped responding for $>15 \mathrm{~min}$; data for vrDD-DL mice from our previous publication were reanalyzed accordingly. The impairment in the acquisition of an operant conditioning task was the same for both vrDD-VM and vrDD-DL mice.

To evaluate the behavior of mice with DA signaling restricted to only part of the striatum and hence examine whether DA signaling in that brain area can support specific motivational, locomotor, and cognitive functions, we restored Th gene expression in DD mice specifically to dopaminergic neurons that project to the medial striatum. This strategy is fundamentally different from the typical approaches that set out to prevent DA signaling in specific brain regions to assess where DA signaling is necessary to facilitate normal behavior (Ungerstedt, 1971; Sokolowski and Salamone, 1998; Dickinson et al., 2000; Baldo et al., 2002). Although we refer to the mice studied here as vrDD-VM mice based on the site of injection, the mice have DA signaling restored to much of the medial striatum as described below. Nevertheless, there would be no DA signaling in the PFC, hippocampus, amygdala, or hypothalamus.

DD mice can learn certain behaviors like conditioned place preference for morphine (Hnasko et al., 2005), cocaine (Hnasko et al., 2007), and L-Dopa (M. Darvas, unpublished data), a simple water escape task (Denenberg et al., 2004), and a spatial T-maze task (Robinson et al., 2005) even in the absence of DA signaling. However, they are unable to learn operant lever pressing for food rewards (Robinson et al., 2007), the novel object, Morris water 
maze, or cue-dependent U-maze (Darvas and Palmiter, 2009). Because DD mice are extremely inactive and unmotivated and will die of starvation without daily L-Dopa injections (Zhou and Palmiter, 1995; Palmiter, 2008), we have developed a procedure that allows discriminating between failure of DD mice to learn or to perform tasks. DD mice are trained in the absence of DA signaling but stimulated to locomote by caffeine injections, and then they are tested after training when DA signaling is restored with L-Dopa. If they have learned the task with caffeine but without DA, but failed to show their learning, then they should perform well after restoration of DA signaling. Together with our previous report about operant conditioning in DD mice (Robinson et al., 2007), we demonstrate here that DD mice that were treated with L-Dopa during both training and test sessions could perform the novel object, Morris water maze, or cuedependent $\mathrm{U}$-maze. Thus, any deficits in these tasks are likely attributable to acute dopamine deficiency and not to developmental abnormalities caused by the genetic manipulations.

Our finding that viral injections into the VM striatum resulted in approximately equal restoration of DA content in both the VM and DM striatum, whereas in the midbrain the expression was predominantly restored to DA neurons of the VTA with only sparse restoration in the SNc indicates that VTA DA neurons not only project to the ventral striatum but also send a substantial number of projections to the DM striatum as well, thus delineating one contiguous DA projection area in the medial striatum. This observation is consistent with reports from retrograde labeling experiments, in which $\sim 15 \%$ of labeled terminals in the dorsal striatum originated from DA cell bodies in the VTA (Ikemoto, 2007). Furthermore, our data suggest that DA neurons projecting from the VTA have a widespread arborization within the striatum, which is consistent with the huge striatal arborization of individual DA neurons that project from the subSNc (Matsuda et al., 2009). Moreover, this DA projection area is congruent with a medial zone of medium spiny neurons (MSNs) that are grouped together according to their afferent inputs from cortical, thalamic, hippocampal, and amygdaloid regions (Voorn et al., 2004). Although DA signaling was primarily restored to the medial striatum, there may be a very low level of DA signaling in other striatal regions as indicated by the low level of TH staining and low, but measurable, DA content in the lateral striatum. We were unable to discern any correlation between behavioral performance in the various tasks and the extent of DA restoration in different brain regions.

A

E
Figure 3. Restoration of visuospatial function, spatial memory, and discriminatory learning in vrDD-VM mice. Object memory was measured by recording preference for a novel object over a sample object $24 \mathrm{~h}$ after habituation to the sample object. $A$, Percentage of total exploration time spent with the novel object in sham control $(n=8)$, DD mice that were habituated to the sample object after stimulation with caffeine and tested for object memory after restoration of DA signaling with L-Dopa $(n=7)$, DD mice that were both habituated and tested for object memory after injection with L-Dopa $(n=6)$, and vrDD-VM mice $(n=10)$. $B$, Object exploration time per sample object during the first habituation trial by sham control $(n=8)$, caffeine-treated DD mice $(n=7)$, L-Dopa-treated DD mice $(n=6)$, and vrDD-VM mice $(n=10)$. C, Latency to escape to a hidden platform in a Morris water maze by sham control $(n=10)$, caffeine-treated DD mice $(n=$ 7), L-Dopa-treated DD mice $(n=6)$, and vrDD-VM mice $(n=10)$. $\boldsymbol{D}$, Swim speed in a Morris water maze by sham control $(n=10)$, caffeine-treated DD mice $(n=7), \mathrm{L}$-Dopa-treated DD mice $(n=6)$, and vrDD-VM mice $(n=10)$. $\boldsymbol{E}, \boldsymbol{F}$, Time spent searching in the quadrants of the Morris water maze after $4 \mathrm{~d}$ of training $(\boldsymbol{E})$ and after $8 \mathrm{~d}$ of training $(\boldsymbol{F})$ by sham control $(n=8)$, DD mice that were trained after stimulation with caffeine and tested after injection with L-Dopa $(n=7)$, DD mice that were both trained and tested after injection with L-Dopa $(n=6)$, and vrDD-VM mice $(n=10)$. G, Percentage correct choices of sham control $(n=10)$, caffeine-treated DD mice $(n=7)$, L-Dopa-treated DD mice $(n=6)$, and vrDD-VM mice $(n=10)$ in the water-based U-maze. Data are expressed as mean \pm SEM. ${ }^{\star} p<0.05 ;{ }^{\star \star} p<0.01$.
Contrary to observations from rodent models of Parkinson's disease, in which lesioning of DA neurons in the SNc results in deficits of visuospatial function and memory (Da Cunha et al., 2002; Mura and Feldon, 2003; De Leonibus et al., 2007), we did not observe any major deficits in visuospatial function or spatial memory in vrDD-VM mice, even though both the extent of TH staining as well as the DA depletion in the striatum were quite similar between those studies and our genetic model. A major difference between these models is the loss of DA signaling versus DA neuron cell loss, leaving open the possibility that the effects observed in lesioning models might be attributable to loss of 



Figure 4. Acquisition of instrumental lever pressing by vrDD-VM mice. Operant conditioning was assessed in sham control ( $n=10$; white diamonds) and vrDD-VM mice ( $n=9$; black diamonds) using a simple lever-pressing task. $\boldsymbol{A}$, Total number of lever presses for food per training day over a period of $18 \mathrm{~d}$. $\boldsymbol{B}$, Food receptacle entries during the lever-pressing task. $C$, Cumulative number of reinforcers earned per 5 min bin during a $3 \mathrm{~h}$ progressive-ratio training schedule. Data are expressed as mean \pm SEM.

Table 2. Abilities of DD, vrDD-DL, and vrDD-VM mice

\begin{tabular}{llll}
\hline & DD mice & vrDD-DL mice & vrDD-VM mice \\
\hline Feeding & Absent & Restored & Restored \\
Locomotion & Minimal & Restored & Restored \\
Object recognition & Absent & Restored & No object exploration \\
Spatial learning and memory & Absent & Restored & Restored \\
Discriminatory learning & Absent & Restored & Restored \\
Operant conditioning & Absent & Impaired acquisition & Impaired acquisition \\
Motivation to attain food reward & Absent & $\sim 75 \%$ of control & $\sim 35 \%$ of control \\
\hline
\end{tabular}

cotransmitters and/or the responses to neuronal destruction (Willis and Kennedy, 2004; Palmiter, 2008).

Striatal DA acts via presynaptic actions on glutamatergic afferents to MSNs and through postsynaptic actions on the MSNs themselves, thus regulating the glutamatergic input to MSNs (Sesack et al., 2003). This DA modulation of MSNs is highly important for striatal function as several studies report similar effects for blockade of DA signaling and blockade of MSN function in the striatum (Smith-Roe and Kelley, 2000; Corbit et al., 2001; Ishiwari et al., 2004; Bari and Pierce, 2005; Faure et al.,
2005). One hypothesis about the striatal function of DA assumes that the striatum is organized in four regions that underlie different association processes that are posited to play a key role in behavioral variation and selection (Ikemoto, 2007). Projections to the VM striatum are proposed to be important for pavlovian types of associations linking cues to particular outcomes. The dorsal striatum is assumed to be divided in a medial system that supports action-goal associations and a lateral system participating in stimulus-response associations. Both these systems are thought to contribute to behavioral selection and are an important part of instrumental learning. One corollary of this theoretical framework is the proposition of a serial cascade of striato-nigralstriatal connectivity through which neuronal signaling from the VM striatum exerts control over processes in DL striatal regions, promoting the transition from goal-directed to habit-driven behaviors (Everitt and Robbins, 2005; Vanderschuren et al., 2005; Belin and Everitt, 2008). But our recent finding that mice with DA signaling restored exclusively to the DL striatum have intact visuospatial and discriminatory learning suggests that this serial processing is not an absolute requirement for learning (Darvas and Palmiter, 2009). Although DA signaling in the DL striatum allowed the mice to learn an instrumental leverpressing task (Darvas and Palmiter, 2009), acquisition was greatly delayed, which might be attributable to a lack of DA in the DM striatum. Yet our finding that mice that have DA signaling only in the medial striatum still retain a substantial deficit in acquiring an instrumental task argues that proper acquisition of an instrumental response relies on signaling to both the medial and DL striatal areas and that later on the expression of the learned behavior can be supported by either two of these areas. Indeed, experiments in which MSNs were inactivated temporarily with $\mathrm{GABA}_{\mathrm{A}}$ agonists provide evidence that the ventral striatum might only transiently facilitate early learning, because during later phases of learning inactivation of the nucleus accumbens had only minor effects (Smith-Roe and Kelley, 2000; Hernandez et al., 2002; Ito et al., 2004; Atallah et al., 2007). However, it is also possible that restoration of $\mathrm{DA}$ to levels higher than those found in vrDD-VM mice is needed to overcome the deficits in operant conditioning that we observed here.

Interestingly, comparison of the abilities of both vrDD-DL and vrDD-VM mice reveals that, with the exception of object exploration, both striatal areas are capable of supporting the same behaviors. This suggests that both spatial, discriminatory, and instrumental learning as well as spatial reference memory do not depend on dopamine signaling in a confined striatal area, even though DL or medial striatum have substantially different neuronal connections (Voorn et al., 2004). Signaling in these areas might still be based on different cognitive processes but support mastery of the cognitive tasks equally well. Future experiments will be necessary to determine whether the mouse behaviors observed with these rescued mice are goal directed or habit driven.

Together with evidence for the engagement of parallel striatal processes during spatial, procedural, and cue-dependent learning from previous reports (Devan and White, 1999; Hikosaka et al., 1999), our results fit well with the view that the learning process is very dynamic and recruits parallel neural circuits including the medial and DL regions of the striatum (Graybiel, 2008). This hypothesis does not preclude the possibility that once a behavior has become a habit that it will then rely primarily on DA signaling to the DL striatum or even extrastriatal areas. Another conclusion from our comparison of DA signaling in the DL and medial stri- 
atum of virally rescued DD mice is that motivation to engage in instrumental behavior appears to be dependent on signaling in different striatal subregions and that the drive to engage in explorative behavior might rely more on the DL striatum. However, the mechanisms underlying these differences between DA signaling in the DL and medial striatum are not necessarily equal; the reduced performance under a progressive-ratio schedule can result from both an impaired motivation and/or reduced incentive value of the reinforcer. The deficit seen in vrDD-VM mice could still be attributable to a motor deficit. Future studies probing the locomotor skills necessary for lever pressing in both vrDD-DL and vrDD-VM mice will resolve this issue.

\section{References}

Atallah HE, Lopez-Paniagua D, Rudy JW, O’Reilly RC (2007) Separate neural substrates for skill learning and performance in the ventral and dorsal striatum. Nat Neurosci 10:126-131.

Baldo BA, Sadeghian K, Basso AM, Kelley AE (2002) Effects of selective dopamine D1 or D2 receptor blockade within nucleus accumbens subregions on ingestive behavior and associated motor activity. Behav Brain Res 137:165-177.

Bari AA, Pierce RC (2005) D1-like and D2 dopamine receptor antagonists administered into the shell subregion of the rat nucleus accumbens decrease cocaine, but not food, reinforcement. Neuroscience 135:959-968.

Baunez C, Robbins TW (1999) Effects of dopamine depletion of the dorsal striatum and further interaction with subthalamic nucleus lesions in an attentional task in the rat. Neuroscience 92:1343-1356.

Belin D, Everitt BJ (2008) Cocaine seeking habits depend upon dopaminedependent serial connectivity linking the ventral with the dorsal striatum. Neuron 57:432-441.

Björklund A, Dunnett SB (2007) Dopamine neuron systems in the brain: an update. Trends Neurosci 30:194-202.

Chudasama Y, Robbins TW (2006) Functions of frontostriatal systems in cognition: comparative neuropsychopharmacological studies in rats, monkeys and humans. Biol Psychol 73:19-38.

Corbit LH, Muir JL, Balleine BW (2001) The role of the nucleus accumbens in instrumental conditioning: evidence of a functional dissociation between accumbens core and shell. J Neurosci 21:3251-3260.

Da Cunha C, Angelucci ME, Canteras NS, Wonnacott S, Takahashi RN (2002) The lesion of the rat substantia nigra pars compacta dopaminergic neurons as a model for Parkinson's disease memory disabilities. Cell Mol Neurobiol 22:227-237.

Dalley JW, Cardinal RN, Robbins TW (2004) Prefrontal executive and cognitive functions in rodents: neural and neurochemical substrates. Neurosci Biobehav Rev 28:771-784

Darvas M, Palmiter RD (2009) Restriction of dopamine signaling to the dorsolateral striatum is sufficient for many cognitive behaviors. Proc Natl Acad Sci U S A 106:14664-14669.

De Leonibus E, Pascucci T, Lopez S, Oliverio A, Amalric M, Mele A (2007) Spatial deficits in a mouse model of Parkinson disease. Psychopharmacology (Berl) 194:517-525.

Denenberg VH, Kim DS, Palmiter RD (2004) The role of dopamine in learning, memory, and performance of a water escape task. Behav Brain Res 148:73-78.

Devan BD, White NM (1999) Parallel information processing in the dorsal striatum: relation to hippocampal function. J Neurosci 19:2789-2798.

Dickinson A, Smith J, Mirenowicz J (2000) Dissociation of Pavlovian and instrumental incentive learning under dopamine antagonists. Behav Neurosci 114:468-483.

Everitt BJ, Robbins TW (2005) Neural systems of reinforcement for drug addiction: from actions to habits to compulsion. Nat Neurosci 8:1481-1489.

Faure A, Haberland U, Condé F, El Massioui N (2005) Lesion to the nigrostriatal dopamine system disrupts stimulus-response habit formation. J Neurosci 25:2771-2780.

Featherstone RE, McDonald RJ (2004) Dorsal striatum and stimulusresponse learning: lesions of the dorsolateral, but not dorsomedial, striatum impair acquisition of a simple discrimination task. Behav Brain Res 150:15-23.
Gorski JA, Balogh SA, Wehner JM, Jones KR (2003) Learning deficits in forebrain-restricted brain-derived neurotrophic factor mutant mice. Neuroscience 121:341-354.

Graybiel AM (2008) Habits, rituals, and the evaluative brain. Annu Rev Neurosci 31:359-387.

Hernandez PJ, Sadeghian K, Kelley AE (2002) Early consolidation of instrumental learning requires protein synthesis in the nucleus accumbens. Nat Neurosci 5:1327-1331.

Hikosaka O, Nakahara H, Rand MK, Sakai K, Lu X, Nakamura K, Miyachi S, Doya K (1999) Parallel neural networks for learning sequential procedures. Trends Neurosci 22:464-471.

Hnasko TS, Sotak BN, Palmiter RD (2005) Morphine reward in dopaminedeficient mice. Nature 438:854-857.

Hnasko TS, Perez FA, Scouras AD, Stoll EA, Gale SD, Luquet S, Phillips PE, Kremer EJ, Palmiter RD (2006) Cre recombinase-mediated restoration of nigrostriatal dopamine in dopamine-deficient mice reverses hypophagia and bradykinesia. Proc Natl Acad Sci U S A 103:8858-8863.

Hnasko TS, Sotak BN, Palmiter RD (2007) Cocaine-conditioned place preference by dopamine-deficient mice is mediated by serotonin. J Neurosci $27: 12484-12488$.

Ikemoto S (2003) Involvement of the olfactory tubercle in cocaine reward: intracranial self-administration studies. J Neurosci 23:9305-9311.

Ikemoto S (2007) Dopamine reward circuitry: two projection systems from the ventral midbrain to the nucleus accumbens-olfactory tubercle complex. Brain Res Rev 56:27-78.

Ishiwari K, Weber SM, Mingote S, Correa M, Salamone JD (2004) Accumbens dopamine and the regulation of effort in food-seeking behavior: modulation of work output by different ratio or force requirements. Behav Brain Res 151:83-91.

Ito R, Robbins TW, Everitt BJ (2004) Differential control over cocaineseeking behavior by nucleus accumbens core and shell. Nat Neurosci 7:389-397.

Kremer EJ, Boutin S, Chillon M, Danos O (2000) Canine adenovirus vectors: an alternative for adenovirus-mediated gene transfer. J Virol 74:505-512.

Matsuda W, Furuta T, Nakamura KC, Hioki H, Fujiyama F, Arai R, Kaneko T (2009) Single nigrostriatal dopaminergic neurons form widely spread and highly dense axonal arborizations in the neostriatum. J Neurosci 29:444-453.

McFarland K, Ettenberg A (1995) Haloperidol differentially affects reinforcement and motivational processes in rats running an alley for intravenous heroin. Psychopharmacology (Berl) 122:346-350.

Mura A, Feldon J (2003) Spatial learning in rats is impaired after degeneration of the nigrostriatal dopaminergic system. Mov Disord $18: 860-871$.

Nakamura K, Hikosaka O (2006) Role of dopamine in the primate caudate nucleus in reward modulation of saccades. J Neurosci 26:5360-5369.

O’Doherty J, Dayan P, Schultz J, Deichmann R, Friston K, Dolan RJ (2004) Dissociable roles of ventral and dorsal striatum in instrumental conditioning. Science 304:452-454.

Palmiter RD (2008) Dopamine signaling in the dorsal striatum is essential for motivated behaviors: lessons from dopamine-deficient mice. Ann N Y Acad Sci 1129:35-46.

Robinson S, Sandstrom SM, Denenberg VH, Palmiter RD (2005) Distinguishing whether dopamine regulates liking, wanting, and/or learning about rewards. Behav Neurosci 119:5-15.

Robinson S, Rainwater AJ, Hnasko TS, Palmiter RD (2007) Viral restoration of dopamine signaling to the dorsal striatum restores instrumental conditioning to dopamine-deficient mice. Psychopharmacology (Berl) 191:567-578

Sesack SR, Carr DB, Omelchenko N, Pinto A (2003) Anatomical substrates for glutamate-dopamine interactions: evidence for specificity of connections and extrasynaptic actions. Ann N Y Acad Sci 1003:36-52.

Smith-Roe SL, Kelley AE (2000) Coincident activation of NMDA and dopamine $D_{1}$ receptors within the nucleus accumbens core is required for appetitive instrumental learning. J Neurosci 20:7737-7742.

Sokolowski JD, Salamone JD (1998) The role of accumbens dopamine in lever pressing and response allocation: effects of 6-OHDA injected into core and dorsomedial shell. Pharmacol Biochem Behav 59:557-566. 
Szczypka MS, Kwok K, Brot MD, Marck BT, Matsumoto AM, Donahue BA, Palmiter RD (2001) Dopamine production in the caudate putamen restores feeding in dopamine-deficient mice. Neuron $30: 819-828$

Ungerstedt U (1971) Adipsia and aphagia after 6-hydroxydopamine induced degeneration of the nigro-striatal dopamine system. Acta Physiol Scand Suppl 367:95-122.

Vanderschuren LJ, Di Ciano P, Everitt BJ (2005) Involvement of the dorsal striatum in cue-controlled cocaine seeking. J Neurosci 25:8665-8670.

Voorn P, Vanderschuren LJ, Groenewegen HJ, Robbins TW, Pennartz CM (2004) Putting a spin on the dorsal-ventral divide of the striatum. Trends Neurosci 27:468-474.

Willis GL, Kennedy GA (2004) The implementation of acute versus chronic animal models for treatment discovery in Parkinson's disease. Rev Neurosci 15:75-87.

Wise RA (2004) Dopamine, learning and motivation. Nat Rev Neurosci 5:483-494.

Wolterink G, Phillips G, Cador M, Donselaar-Wolterink I, Robbins TW, Everitt BJ (1993) Relative roles of ventral striatal D1 and D2 dopamine receptors in responding with conditioned reinforcement. Psychopharmacology (Berl) 110:355-364.

Yin HH, Ostlund SB, Balleine BW (2008) Reward-guided learning beyond dopamine in the nucleus accumbens: the integrative functions of corticobasal ganglia networks. Eur J Neurosci 28:1437-1448.

Zhou QY, Palmiter RD (1995) Dopamine-deficient mice are severely hypoactive, adipsic, and aphagic. Cell 83:1197-1209. 